\title{
Observação documental - O registro imagético e sonoro da vivência nas escadarias do centro do Porto
}

\author{
Ana Clara Nunes Roberti \& Daniel Brandão*
}

Resumo: Este artigo é uma reflexão sobre as metodologias documentais na experiência realizada sobre o registro visual do cotidiano das Escadas das Verdades e do Codeçal, no Centro do Porto, que teve como motivação a permeabilidade entre o público e o privado no modo de vida local. A partir de um trabalho de quase dois anos (2013 a 2015), foi realizado um documentário no âmbito do Mestrado em Design da Imagem na Universidade do Porto.

Palavras-chave: documentário, patrimônio cultural; cinema; design da imagem; observação participante; metodologias documentais.

Resumen: Este artículo es una reflexión sobre las metodologías documentales del registro visual de lo cotidiano en Escadas das Verdades e Codeçal, en el centro de Porto, un trabajo de cerca de dos años (2103-2015) que tuvo como motivación la permeabilidad entre lo público y lo privado en el modo de vida local y se hizo un documental incluido en el Master en Design de Imagen, Universidad de Porto.

Palabras clave: documental, patrimonio cultural; cine; design de imagen; observación participante; metodologías documentales.

Abstract: This article is a reflection on the documentary methodologies in the experiment carried out by the visual record of the everyday life at the Stairs of Verdade and Codeçal, in downtown Porto, who was motivated by the permeability between the public and the private in the local way of life. From a work of almost two years (2013-2015), it was made a documentary included in the Master in Image Design, Porto University.

Keywords: documentary, cultural heritage; cinema; image design; participant observation; documental methodologies.

Résumé: Cet article est une réflexion sur l'enregistrement visuel de la vie quotidienne des Escaliers de Vérités et Codeçal, dans le centre de Porto, un travail qui s'est étalé sur près de deux ans et qui a pour motivation la perméabilité entre le public et le privé dans le mode de vie local.

Mots-clés: documentaire; patrimoine culturel; observation participante.

\footnotetext{
* Ana Clara Nunes Roberti: Doutoranda. Universidade do Porto, Faculdade de Belas Artes do Porto, Doutoramento em Design. 4049-021, Porto, Portugal. E-mail: nr.anaclara@gmail.com

Daniel Brandão: Instituto Politécnico do Cávado e do Ave, Escola Superior de Design, Departamento de Arte e Comunicação. 4750-810, Barcelos, Portugal. E-mail: daniel.c.brandao@gmail.com
}

Submissão do artigo: 31 de dezembro de 2015. Notificação de aceitação: 15 de fevereiro de 2016. 


\section{Introdução}

Algumas paisagens humanas parecem estar, particularmente, vivas. O centro da cidade do Porto possui uma série de escadarias que são, de uma forma curiosa, cercadas por casas. Apesar de estarem, no momento desta investigação (2013 a 2015), em boa parte abandonadas - muitas casas desabitadas ou em más condições e pouco fluxo de pessoas a transitar pelas escadas - a vivência humana não faz questão de se esconder e parece, à primeira vista, transbordar.

Bacias, estendais, brinquedos de criança, vasos de plantas. Tudo isso é deixado no chão, logo aos pés ou à cabeça de qualquer um que venha a passar por esse percurso. O público dá lugar ao privado. Tudo o que configura aquele espaço parece discorrer sobre quem nele vive, mesmo não se tratando de suas casas, do ponto de vista físico. O que está à volta, fala de quem por ali está.

As escadas são, do ponto de vista morfológico, irregulares, íngremes e compostas de uma quantidade significativa de degraus. A descrição leva a pensar que se trata de um local desconfortável para se estar, mas a realidade não cumpre tais expectativas. Os moradores passam boa parte do tempo do lado de fora de casa, sentam-se por horas entre um degrau e outro para conversar, apenas para tomar um pouco de sol ou fumar um cigarro. As crianças brincam e correm pelas escadarias. As mães lavam e estendem roupa, guardam objetos, tal como no quintal de casa.

A primeira vez que a investigadora deu conta deste cenário particular foi em uma deriva pela cidade. Desde o primeiro momento, as escadas foram capazes de instigar curiosidade. É como entrar, de repente, em um grande quintal com vistas privilegiadas para o meio da cidade. O interesse e as constantes descobertas, deram origem à investigação ${ }^{1}$ que aqui se apresenta.

Estas comunidades foram capazes de usar os degraus como paredes e se isolarem da agitação urbana que fica a poucos metros dali. Entretanto, ao longo da investigação, compreendeu-se que o que entristece os moradores é justamente o abandono do local, muitos acreditam que "antes é que era". Dessa forma, a pesquisa foi acrescida por outros caminhos, complementares entre si e enriquecedores.

O documentário ${ }^{2}$ foi a ferramenta eleita para organizar e transmitir o conhecimento adquirido. A escolha deveu-se às preferências e práticas pessoais da investigadora, com o apoio do co-autor deste artigo, e pela liberdade que

1. Investigação desenvolvida no âmbito do Mestrado em Design da Imagem na Faculdade de Belas Artes, da Universidade do Porto, de autoria de Ana Clara Nunes Roberti, sendo orientadores os professores Adriano Rangel e Daniel Brandão.

2. Ver teaser $\mathrm{em}:$ https://vimeo.com/145889232 
esse tipo de linguagem oferece, dando margem para a exploração do tema, sua apresentação e interpretação. Os imprevistos foram constantes e parte complementar do trabalho. O envolvimento com o local e com os moradores revelouse essencial e prosseguiu-se por mais de um ano. A ideia foi usufruir da prática cinematográfica para elaborar a representação de um recorte da realidade de forma singular e subjetiva.

O fato de serem escadas cercadas por casas, já sugere um paradoxo: escadas são essencialmente locais de passagem e acesso para os transeuntes contudo, há pessoas que residem nesse trânsito e, mais do que isso, se apoderam dele.

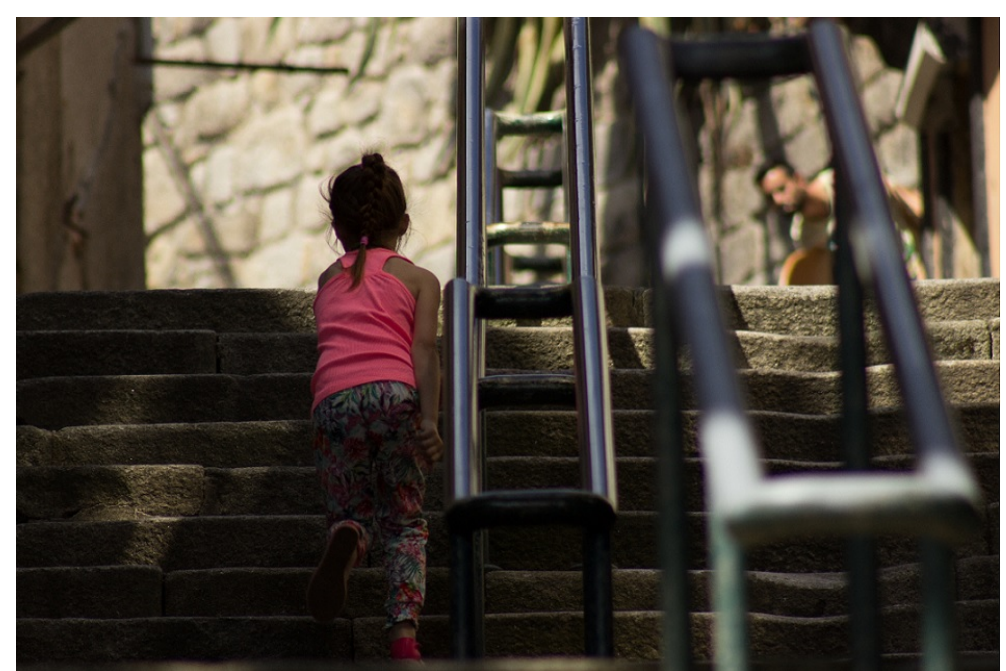

Figura 1. Imagem feita nos primeiros meses de trabalho de campo. Autoria: Ana Clara Roberti

\section{Os limites (ou a falta de) entre o público e o privado}

A maneira como os moradores lidam com o espaço para fora da porta de suas casas parece ser diferente do que acontece de forma geral na restante cidade (Fig. 1 e 2). Não foi preciso estar distante do meio urbano para que a situação fosse diferente. Pelo contrário, as escadarias aqui estudadas estão no centro do Porto.

Chega-se à hipótese central da existência de pontos de charneira psicogeográficos. Mede-se as distâncias que efetivamente separam duas regiões de uma cidade, distâncias que podem ter pouquíssima relação com a distância física entre elas. (Debord, 1958: 4). 
As escadas aparecem como potenciadoras deste ambiente. São capazes de impedir que ali passem carros, motos ou outros tipos de veículo. Isso contribui para que as crianças possam estar, sem perigo, a brincar pelo espaço, ainda que sem a supervisão dos pais. As escadas são muitas, o que faz com que quase nenhum transeunte as utilize como passagem do ponto de vista prático; com exceção dos moradores, os que ali passam são turistas ou curiosos. A largura das escadas é menor do que a das ruas, o que torna as casas mais próximas umas das outras e sendo assim, também os vizinhos. Apesar de desconfortáveis para subir e descer, parecem propensas para se sentar e assim, de repente, juntam-se alguns moradores entre os degraus para conversar.

Através, principalmente das imagens, este projeto procurou ressaltar as peculiaridades destas comunidades no que se refere aos limites entre o espaço público e privado. O registro de quase dois anos do cotidiano comum das escadas foi o material trabalhado.

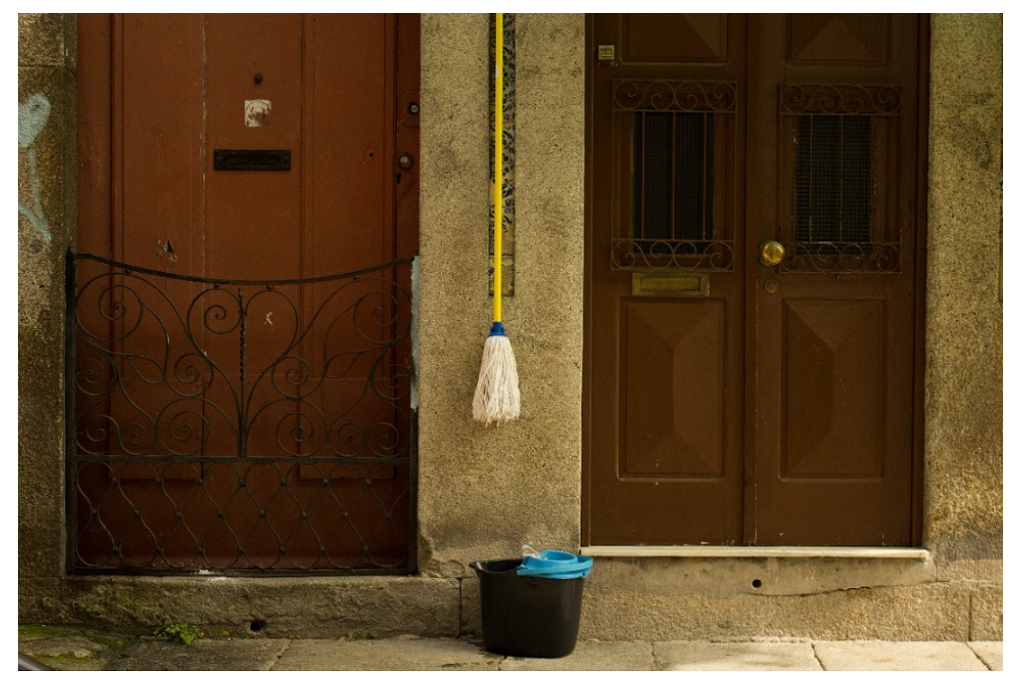

Figura 2. Imagem da faixada de uma das casas das Escadas do Codeçal. Utensílios de limpeza caseiros dispostos como se o espaço exterior à residência fosse ainda parte integrante da mesma.

Autoria: Ana Clara Roberti

\section{Delimitar}

No princípio da investigação constatou-se que havia um número considerável de escadarias habitadas no centro do Porto; boa parte delas, partindo do rio, dá acesso a outras partes da cidade. Como forma de se trabalhar de ma- 
neira mais precisa o objeto de estudo foi preciso delimitar o terreno. Depois de um período de trabalho de campo e análise, foram escolhidas as Escadas das Verdades e as Escadas do Codeçal, ambas pertencentes à freguesia da Sé. A aproximação geográfica entre ambas colaborou para a escolha, sendo uma a continuidade da outra. Além disso, as primeiras derivas, momentos que deram origem ao interesse em elaborar este trabalho, foram feitas por esta região.

\section{Pertinência e urgência do registro}

Este projeto ocupa-se, principalmente, em ter um registro imagético, fundamentado em uma investigação de rigor científico, de comunidades que vêm sendo profundamente alteradas nos últimos anos. Esse processo, no caso das escadarias estudadas, não apresenta sinais de interrupção, pelo contrário, temse agravado. A maior parte dos moradores já saíram de suas casas devido a falta de condições de habitação. Entretanto, as casas deixadas não foram reformadas e tão pouco têm recebido novos moradores. São poucos os que ainda permanecem no local. Moradores antigos dispostos, em boa parte, a se mudar pelos mesmos fatores e ainda pela agravante do metro, que passa na ponte logo acima das casas produzindo muito ruído.

Trata-se de um ambiente rico em história e vivência. Os que ainda insistem em lá viver, talvez já não por muito mais tempo, foram capazes de transmitir um conhecimento importante para esta investigação, que não poderia ser adquirido de outra forma. Esta é uma investigação com caráter de urgência, a preservação do local, que sob difíceis condições ainda sobrevive, foi feita por meio de imagens como forma de salvaguardar essa herança cultural.

\section{O cinema documental como ferramenta}

Primeiro conteúdo, depois forma. Essa foi a ordem de construção deste trabalho, mesmo que a passagem por esses estágios tenha sido rápida a ponto de praticamente fundi-los. O que se pretende esclarecer é que o projeto buscou fazer do tema um bom documentário e não forçar o enquadramento de um assunto no âmbito documental.

O lugar que é representado na tela é um assunto, mas a pessoa que o representa na tela, é outro. Entretanto, o lugar pode influenciar a pessoa e a pessoa o lugar; e já não há distinção entre um e outro. O caso em questão é assim e a riqueza dessa fusão é tamanha que se torna quase o assunto principal do tema por completo. Dentro desse híbrido, moradores e escadas se misturam numa pluralidade de cor e som que parece pedir que uma - várias - imagem em movimento fale um pouco por si. 


\section{Entre a Verdade e o Direto}

Jean Rouch, um dos fundadores do Cinema Vérité (França) é importante para este trabalho na medida em que apostou em um cinema auto crítico e de metodologia reflexiva. A ideia do "assunto" a ser tratado no documentário provocar essa reflexão e poder interferir diretamente no rumo da obra, se aplicou ao longo da investigação em questão desde o momento em que houve contato direto e explícito com os moradores das escadas do centro do Porto. A relação construída com essas pessoas foi espontânea e improvisada do início ao fim.

$\mathrm{Na}$ visão de Rouch, o cinema etnográfico não se posicionava como oposto ao cinema de autor, pelo contrário, ambos poderiam confluir numa mesma obra, expondo a observação participante e, consequentemente, a relação com o outro. "Em seus filmes sentimos a presença de um outro personagem, que é o olhar da câmera, e que apesar de estar externo à cena, vai também conduzir o andamento da história" (Daminello, 2010: 34). O resultado desta experiência documental, conta com a subjetividade, na medida em que apresenta um olhar próprio sobre o tema que se propôs estudar. A intenção deste trabalho nunca foi ter uma postura passiva. Desde os aspectos mais abrangentes, como a escolha do local a ser tratado, até aos detalhes na montagem do filme, afirma-se certo grau inalienável de subjetividade, sem prejuízo do próprio rigor científico do projeto. Entretanto, o que houve foi a associação de duas visões que se misturaram sem hierarquia: a de quem observa e a dos que passaram a, também, observar.

O nosso objetivo [Comité du Film Ethnographique] era de uma grande ambição: iniciar o diálogo entre o rigor científico e a arte cinematográfica. Mas, desde aí, o Filme Etnográfico tornou-se adulto e reconhecido no mundo inteiro sob o nome de Visual Anthropology- Antropologia Visual. (Rouch, 1995: 11).

A câmera de Rouch é participante, leve, vai onde precisa ir. É um instrumento que faz a intermediação entre quem filma e quem é filmado. Uma relação importante que pode, sem problemas, ser notada. "Então, ao invés de usar o zoom, o operador de câmera/diretor pode realmente entrar dentro de seu assunto filmado. Acompanhando ou perseguindo um dançarino, um sacerdote ou um artesão (...)" (Rouch \& Feld, 2003: 39) . Neste trabalho, não há pretensões em fazer com que o espectador se esqueça que ali existe uma câmera. Aliás, é, inclusive, importante que ele se lembre que ela ali está e que tipo de implicações isso causa.

(...) Para mim, a única maneira de filmar é caminhar com a câmera, levando-a onde ela é mais efetiva e improvisando, com ela, outro tipo de balé, tentando fazê-la tão viva quanto as pessoas que se está filmando. Eu considero esta 
improvisação dinâmica como sendo a primeira síntese do cine-olho de Vertov e a câmera participante de Flaherty. (Rouch \& Feld, 2003: 39).

O Direct Cinema (Estados Unidos da América) também libertava o documentário das típicas receitas comerciais, mas de outro modo. O realizador era apenas um observador, enquanto o espectador se esquece que há uma câmera que o separa da realidade retratada. Equipes reduzidas, discretas, com pouca ostentação tecnológica e sempre com a câmera nas mãos.

$\mathrm{O}$ artista do cinema direto almejava a invisibilidade; o artista do cinemaverdade de Rouch era, na maior parte das vezes, um participante declarado. O cineasta do direto representava o papel de um espectador descomprometido; o artista do cinema verdade adotava o comportamento de um provocador. (Barnouw, 1993: 254).

O processo etnográfico deste projeto não se concentrou em apenas um dos movimentos e práticas. Procurou, sem uma ordem de importância específica, mesclá-los de acordo com o que fazia sentido em cada situação. Foi preciso recorrer a uma postura observadora e paciente, ao máximo sem "intromissões", resultando em reflexões e imagens que possam respirar. Ao mesmo tempo, também não houve o receio de deixar a relação com a câmera e com o investigador vulnerável aos olhos de quem assiste. É possível ver as pessoas se dirigirem diretamente a quem está a filmar e ainda ouvi-las a relatar situações em que estiveram com a realizadora, Ana Clara Nunes Roberti. Intervenções, situações criadas e, naturalmente, o trabalho de edição, enfatizam a forma autoral do trabalho.

\section{Outras influências}

Em dosagens diferentes, houve ainda uma série de outros autores e experiências precursoras que contribuíram para a maneira de pensar e lidar com este trabalho. Áreas de estudo multidisciplinares, autores e realizadores, que funcionaram como inspiração, conhecimento ou referências metodológicas

Pela observação intensa: o Mass-Observation, investigação social, que teve como objetivo registrar a vida cotidiana na Grã-Bretanha através do contributo de observadores voluntários, teve início em 1937 e foi polêmico em seu propósito, processo e resultados (Mass Observation, 2004). A polêmica foi devido à técnica adotada, que passava por fazer com que os cidadãos se observassem mutuamente, incutindo um espírito de vigilância. $\mathrm{O}$ interesse pelo registro da vida banal do dia a dia e a dedicação à observação, foram aspectos que aproximaram esta iniciativa deste projeto. A ideia de fazer com que as pessoas olhassem para o seu próprio cotidiano e para o espaço que as cerca é algo que influenciou este trabalho - naturalmente, em outro grau de intensidade e 
através de metodologias diferentes. As anotações feitas pelos cidadãos sobre o que era observado na vida cotidiana, remete ao que foi feito neste trabalho, com um diário criado não apenas para as entrevistas e notas das reuniões com estudiosos da área, mas também para registrar os aspectos observados em cada visita ao local de estudo onde foi construído o filme.

Pela deriva e pela passagem: tendo em conta que este projeto surgiu a partir de derivas e deambulações e teve sequência numa espécie de deriva guiada, é possível estabelecer relações estreitas com o trabalho de Guy Debord. "O campo espacial de uma 'deriva' pode ser delimitado com precisão ou pode ser vago, dependendo de se o objetivo é estudar um terreno ou desorientar-se emocionalmente" (Debord, 1958: 3). Existe a consciência de que há consequências psicogeográficas envolvidas no processo deste trabalho. Atravessar um espaço público em busca de interpretá-lo, fazer questionamentos aos que lá estão é, de alguma forma, provocar. Durante as sucessivas derivas, foi preciso equilibrar constantemente o improviso, o natural e o rigor científico, de forma a ter um controle flexível da situação, “(...) a 'deriva' inclui ao mesmo tempo o deixar-correr e a sua necessária contradição: o domínio das variações psicogeográficas através do conhecimento e cálculo das suas possibilidades" (Debord, 1958: 1).

Em Sur le passage de quelques personnes à travers une assez courte unité de temps (1959), Debord discorre sobre conceitos teoricamente interessantes para este trabalho e apresenta, também, uma edição de vídeo peculiar. A montagem não se compromete com a linearidade, mas sim procura transmitir ideias e causar impacto visual. Obras bem-sucedidas desse tipo encorajam a construção de outras. A "busca de diferentes usos da paisagem urbana" (Debord, 1959) é, de forma abrangente, a grande base para este trabalho.

Pelo histórico e pelo poético: por meio da expressividade metodológica, este projeto propôs explorar a narratividade poética do histórico, busca esta, enfatizada por Walter Benjamin (Benjamin, 2006). É dessa forma, que as suas ideias e conceitos serviram de fonte para este trabalho. É possível dizer que um dos grandes métodos utilizados foi a própria passagem. Desde a passagem literal e física, nas incontáveis vezes que a realizadora Ana Clara passou pelo espaço estudado, até aos seus conceitos mais abstratos. Sendo uma interpretação possível de uma realidade que tem sua própria história, o resultado desta pesquisa e a obra final são, nada mais, do que uma passagem por um cenário que continua a existir de forma contínua e independente. Uma passagem expressa de forma poética sobre uma comunidade urbana específica. Fragmentos de uma realidade, unidos de forma a criar uma determinada versão sobre esta, com a finalidade de comunicá-la. "O conhecimento existe apenas em lampe- 
jos. O texto é trovão que segue ressoando por muito tempo" (Benjamin, 2006: 499).

Por carregar uma câmera: houve um momento, durante a captura de material áudio e visual, em que foi preciso questionar a pertinência da realização de entrevistas estruturadas. Pelo seu caráter jornalístico, rígido e pouco convidativo, chegou-se à conclusão de que a entrevista feita deste modo não seria a técnica ideal para a recolha de informação, mas sim a entrevista semiestruturada, a conversa, ou até mesmo a entrevista não-estruturada, assumida aqui como conversas exploratórias, pelo seu carácter informal que coloca o outrora "entrevistado" numa posição mais confortável e dialogante para com o "entrevistador". Isto proporcionou material mais rico, nomeadamente no que toca à própria narrativa. As obras do cineasta Eduardo Coutinho foram referência para este processo de decisão e facilitaram bastante os passos seguintes. Em filmes como Edifício Master (Coutinho, 2002) e, principalmente, O fim e o princípio (Coutinho, 2006), Coutinho faz perguntas sem receio do que possa parecer, das reações que virão ou da presença de quem está do outro lado da câmera.

A maioria dos que fazem documentários fazem, efetivamente, entrevistas. As entrevistas têm um lado jornalístico e de depoimento. Entrevistas e depoimentos são coisas para a História. São coisas que se fazem com especialistas. E eu trabalho com pessoas comuns. A pessoa conta um fato histórico e, se ele é verdadeiro ou não, deixa de ter importância. (Coutinho, 2009: 128).

Em $O$ fim e o princípio (2006) não há roteiro, apenas um lugar, que não era familiar para o realizador. O que viria a ser conhecido e o processo dessa tomada de conhecimento seria, no fim, o filme. A câmera, a presença do realizador e as perguntas que foram feitas, não comprometeram a construção de um filme que conseguiu fugir dos padrões jornalísticos e televisivos. Ter uma experiência com esse resultado, contribuiu para encorajar o uso de algumas técnicas antigas neste trabalho, mas de maneira diferente. A câmera ficou mais leve e as palavras menos ensaiadas.

\section{Métodos adotados}

O percurso deste trabalho documental foi marcado pelo aperfeiçoamento dos métodos mediante a reflexão proporcionada pelo trabalho de campo. Uma espiral de aprendizado constantemente verificada ao longo do processo de criação do próprio documentário. "Nesse tipo de antropologia, intitulada por Rouch de 'shared anthropology', o filme deve explorar uma metodologia refle- 
xiva de autocrítica e feedback. Pela qual o assunto filmado deverá intervir na própria concepção do filme." (Brandão, 2014: 110). ${ }^{3}$

Teoria e prática não seguiram uma ordem pré-definida, influenciaram-se mutuamente e foram, ambas, requisitadas ao longo desta trajetória. Os avanços e recuos revezaram-se consoante aos resultados da abordagem intuitiva no trabalho de campo. Algumas estratégias foram desenhadas de maneira prévia, mas acabaram por se revelar inadequadas, tendo sido remodeladas depois de testadas e, em alguns casos, abdicadas.

A comunidade urbana em questão tem uma maneira muito própria de ser e, como uma espécie de micro cosmos, funciona consoante uma dinâmica já enraizada e pouco convidativa a terceiros. Dessa forma, os métodos utilizados para prosseguir com essa investigação não poderiam ser elaborados sem uma forte aliança entre o intuitivo, o empírico e o teórico.

Não seria possível, ou pelo menos legítimo, investigar o modo de vida desta comunidade sem lá estar, sem conviver com o espaço e com as pessoas. Tratando-se de um corpo social inicialmente fechado foi preciso recorrer a uma intuição investigativa, na qual os métodos de abordagem adotados foram variados e escolhidos tendo em conta a imprevisibilidade de cada momento, até ser possível recolher um conteúdo sólido para se trabalhar no documentário. Todo esse processo envolvido em tais conceitos sensibilizadores tende a ser acompanhado e selado com um embasamento teórico dos que já fizeram este tipo de experiências (Flick, 2005), ou dos que possibilitaram um campo fértil de estudos para se fazer associações e compreender o tema.

A acelerada mudança social e a consequente diversidade dos universos de vida confrontam cada vez mais os cientistas com novos contextos sociais e novas perspetivas. Estas são para eles uma novidade tao grande que as metodologias dedutivas tradicionais -derivar dos modelos teóricos as questões e hipóteses da investigação e submetê-las ao teste dos resultados empíricos — fracassam na diferenciação dos assuntos. A investigação é, por isso, cada vez mais forçada a recorrer a estratégias indutivas: em vez de partir das teorias para o teste empírico, o que se exige são "conceitos sensibilizadores" para abordar os contextos sociais que se quer estudar. (Flick, 2005: 2).

\section{Relacionar através da imagem e do som}

Neste projeto a imagem é, além do resultado, o meio. No processo de aproximação e envolvimento com o local e os moradores, a imagem foi utilizada de modo a atrair a atenção, como um elemento agregador. Os dispositivos capazes de captar som e imagem deixaram de ser intrusos, para se tornarem ferramentas

3. Tradução livre. 
de legitimidade e confiança. Depois dos moradores verem imagens produzidas sobre eles ou de conhecidos, passaram a ver com outros olhos este estudo, momentos que tiveram lugar após mais de um ano do início da investigação. Levar e entregar centenas de fotografias dessas pessoas e do local onde vivem para que pudessem, elas próprias, ver a maneira como estavam a ser observadas e tornar o trabalho "palpável", contribuiu para receber não apenas credibilidade, mas também algum tipo de afetividade. Depois desses momentos e principalmente próximo do fim do processo investigativo, começou a haver, inclusive, pedidos para que se fotografassem os filhos ou momentos específicos nas escadas. A crescente aproximação e a intenção de mostrar o quão valioso eram as imagens neste projeto, permitiram o acesso a fotografias pessoais de algumas famílias. Material obtido ao fim de um mês de diálogo direto e convivência mais próxima com os moradores, que se revelou importante para a análise e o estudo da investigação, mas também como uma prova de confiança e liberdade oferecida à investigadora.

\section{Participação}

A investigação tem como base um lugar específico, e o que o define são justamente as pessoas que o habitam. A forma como os moradores e o espaço integram este projeto é quase como uma espécie de simbiose, que reflete o conjunto que é essa comunidade urbana.

Entretanto, confirmando a alerta dos que já estiveram no local, essa relação demorou mais tempo do que o previsto para ser construída, atravessando resistências de diferentes tipos. O estreitamento dos laços com os moradores concretizou-se seis meses depois do início do trabalho de campo. Mesmo recorrendo a estratégias de participação simples, parecia cada vez mais complicado conseguir a interação e colaboração dos moradores no projeto. Entretanto, com insistência (principalmente presencial) e com alguma paciência, foi possível construir este projeto com uma considerável e importante dose de participação. As crianças foram fundamentais para isso, tal como pode ser verificado no trabalho audiovisual. A franqueza das crianças fez com que, inicialmente, fossem as mais desconfiadas; se mostravam claramente incomodadas com a presença "estranha" que as observava. Entretanto, com o tempo e depois de perguntarem o que queriam saber sobre a realizadora e o projeto, foram as que estabeleceram relações mais próximas. A espontaneidade dessas crianças é transmitida sem dificuldades e possibilita que se olhe para o espaço de outra forma. 


\section{Observação participante e não participante}

O trabalho documental que se apresenta está diretamente ligado a três áreas de investigação: a geografia cultural (o estudo do comportamento humano por meio do espaço), a antropologia visual (ramo da antropologia cultural que estuda a produção de imagens; observa e expressa o real pela imagem) e a etnografia (a coleta de dados característicos sobre uma comunidade). A combinação dessa tríade leva à adoção de uma prática fundamental para o desenvolvimento do documentário: a observação participante.

Entretanto, a forma de se observar não foi a mesma ao longo deste percurso. Foi aplicada uma estratégia que visou entender, primeiro com uma presença sútil e o mais perto da invisibilidade possível, como as pessoas que vivem naquelas escadas lidam com o local. O cotidiano vulgar, horários, movimentação, visitas desejadas ou não, ocupação, relação entre os vizinhos, etc. Essa suposta discrição propiciou o olhar sem as alterações que a presença de uma câmera, ou até mesmo a apresentação do projeto em questão, poderia provocar.

Essa postura possibilitou que os moradores olhassem para si próprios por meio das imagens feitas enquanto não sabiam que estavam a ser "olhados". A comparação da informação colhida antes e depois da relação direta com estes foi interessante para a investigação, o que inclui os próprios moradores, admirados ao olharem para si próprios. Nesse sentido, foram desenvolvidos, ao longo da construção do filme, dois diários: um de palavras (um caderno de anotações) e um de imagens (um arquivo online organizado por visitas ao local).

Aos poucos, a participação no próprio ambiente que estava a ser estudado foi sendo alterada. Este se tornou cada vez mais familiar, tendo em conta a dinâmica cotidiana das escadas: horários de movimentação e momentos quase completamente desertos; quem saía de casa, a que horas e porquê; quando era o fluxo mais intenso dos turistas; quem era parente de quem entre as casas; a relação entre os vizinhos; o nome das pessoas; e até mesmo a realizadora ser chamada pelo nome e questionada sobre o motivo pelo qual não havia aparecido nos últimos dias.

\section{Entrevistas}

Encontros com estudiosos das áreas de interesse, pessoas que já tiveram projetos ou algum tipo de experiência com o local e, naturalmente, com as pessoas diretamente ligadas às escadas (os moradores), foram fundamentais e inclusive parte do próprio desenvolvimento deste trabalho. Essas conversas 
exploratórias contribuíram tanto para elaborar planos estratégicos para o trabalho de campo, quanto para adquirir conhecimento e diferentes visões sobre o local. Ouvir de fontes primárias relatos e ponderações sobre o cotidiano das escadas, foi a forma mais direta de se chegar ao conhecimento e à análise do local, uma forma explícita de se transmitir conhecimento por meio de outros.

\section{Material e equipe de gravação}

No seguimento da recomendação de vários antropólogos e documentaristas, nomeadamente o próprio Jean Rouch, foi opção adotar uma estratégia de rodagem que implicasse a menor quantidade de pessoas possível no terreno, de modo a não interferir com o ambiente da população. Não existiu uma equipe de gravação. A equipe se resumiu à realizadora e o material foi apenas um microfone portátil e um tripé para a câmera. Optou-se por se fazer dessa forma, tendo em vista a inibição que poderia ser causada pelo aparato tecnológico utilizado para a captação de som e imagem e a possibilidade indesejada de se chamar a atenção de outras pessoas. Quanto menos, mais simples e, possivelmente, mais direto, ágil e genuíno.

Não depender de uma equipe foi complicado em muitos momentos, não havia sequer mãos para se segurar outra câmera, mas possibilitou liberdade o suficiente para ir a campo a qualquer hora e por quanto tempo fosse preciso. Muitas vezes, não levar material algum foi a melhor opção, fosse com o objetivo de conversar com as pessoas, fosse para observar sem o compromisso do registro audiovisual. A ideia era produzir o menor ruído possível na comunidade que estava a ser retratada, e poder compreender a sua dinâmica peculiar de uma forma mais íntegra, podendo registrar esse conhecimento a fim de comunicá-lo.

\section{Abordagem intuitiva}

O fato de não estar diretamente familiarizada com o local e não ter tido previamente contato direto com as pessoas que ali viviam, exigiu a adoção de uma estratégia exploratória. É preciso ressaltar que, ainda que explicitada aqui como "intuitiva", tal abordagem era inevitavelmente dotada de algum conhecimento teórico prévio, obtido, por exemplo, através de entrevistas com os que já haviam estudado realidades semelhantes no centro da cidade do Porto, para além dos autores que discutem metodologias antropológicas de terreno. Entretanto, era preciso adequar tal conhecimento à realidade da comunidade urbana em questão, o que só foi possível com exercícios práticos. Foi preciso arriscar diferentes abordagens ao local, algumas bem-sucedidas, outras não tanto. Um 
jogo de avanços e recuos para se compreender por onde ir e porquê. A abordagem intuitiva foi mais intensa, principalmente, até se conseguir encontrar um conteúdo consistente para se explorar. A compreensão de dinâmicas simples do cotidiano local, fez significativa diferença no avanço do processo de investigação, como por exemplo passar a saber a que horas cada pessoa costuma estar do lado de fora de casa (nas escadas), que casas têm relações mais próximas entre si, quais moradores têm parentesco familiar, etc.

Exemplo que ilustra tal momento exploratório, foi o caminho para se descobrir a forma como a realizadora se deveria apresentar pessoalmente, assim como apresentar o próprio projeto aos moradores, principal público-alvo deste trabalho; com quem falar e como falar; qual o local deveria ser escolhido para ser explorado com maior precisão; como coletar material de arquivo; de que maneira conquistar a confiança das pessoas. De certa forma, todas as metodologias adotadas por este projeto estiveram, mesmo que em intensidades diferentes, ligadas à intuição e ao caráter exploratório do trabalho de campo.

\section{O filme}

\section{Planejar é preciso, improvisar ainda mais}

O processo de seleção se inicia já na escolha do tema, desse pedaço de mundo a ser investigado e trabalhado na forma de um filme documentário. Continua com a definição dos personagens e das vozes que darão corpo a essa investigação. (Puccini, 2012: 16).

Quando se trata de um documentário, um roteiro muitas vezes tende a ser incerto no que diz respeito ao objeto a documentar. No caso específico deste projeto foi preciso, como já descrito anteriormente, percorrer um caminho até conquistar, de alguma forma, a confiança daqueles que fazem parte deste trabalho. Não se pode dizer que houve um dia previamente programado para se levar a câmera ao local. Ela esteve quase sempre na mochila, algumas vezes não era sequer utilizada, tudo variou conforme o ambiente das escadas naquele dia, naquela hora.

Ao contrário do que se faz na ficção, as certezas de um set não se aplicam nas gravações de um documentário. Neste, em específico, nem mesmo as entrevistas tiveram hora marcada. As imagens e o áudio foram captados com base num trabalho de campo intenso, imersivo e de carácter evolutivo. Com pouco equipamento para facilitar a mobilidade e a agilidade, foi mais fácil tornar câmera e microfone mais naturais no meio das conversas e situações cotidianas daquele espaço. Tratou-se de uma imersão dupla, da investigadora/realizadora e câmera. 
Entretanto, é preciso ressalvar que foi elaborado um roteiro de ações, ainda que aberto a várias alterações que se vieram a confirmar. Tal roteiro serviu como estratégia de planejamento do trabalho de campo, mas muitas das ações previamente planejadas, necessitaram de ser alteradas ou até mesmo eliminadas, tendo em conta o imprevisto do que se ia encontrando. Essa estratégia foi fundamental para a organização de ideias, otimização do tempo e até mesmo para que fosse possível analisar as mudanças de rumo do projeto ao longo do tempo e suas razões.

O processo de produção, roteiro e filmagens foram contínuos e, sendo assim, se misturaram ao longo do projeto. Pode se dizer, que apenas a edição e a pós-produção foram separados em uma ordem diferente das demais ações.

\section{Apesar e com tudo}

As imagens gravadas e utilizadas no filme, muitas vezes não seguem à risca padrões estéticos pré-definidos. A câmera e o som foram atrás dos momentos e não o contrário.

Se no meio de uma conversa, acontecesse algo que se julgava ser interessante, encontrar um ângulo ou uma luz que parecessem mais adequados esteticamente, ou ainda pedir para que se repetisse algo dito ou qualquer ação, nunca foram consideradas opções, tendo em conta que se poderia comprometer na naturalidade do momento.

Um exemplo dessa forma de abordagem é o momento em que uma moradora, a menina Nádia, resolve jogar uma garrafa de água em si própria e pede permissão à avó, Lala (Fig. 3). O fato aconteceu de repente em meio a uma conversa com Lala. A câmera se move, foca e desfoca, vai atrás da menina e procura retratar o que se passa da forma mais natural possível, sem que ela própria se sentisse incomodada ou disposta a agir especificamente para a câmera. A realizadora não saiu sequer do degrau em que estava sentada com a avó para poder filmar o momento. Sendo assim, houve a continuidade de uma ação espontânea e não a interrupção ou a moldagem desta. A estratégia foi fazer com que a câmera, ou mais do que isso, a ação de gravar, fizesse parte da presença da realizadora. A câmera não estava nunca na altura do rosto, para que pudesse haver um diálogo mais confortável com os moradores, mas sim próxima ao colo, nas mãos, ou mesmo colocada sobre a mochila. O único momento em que se usou um tripé para falar com as pessoas foi durante as "entrevistas". Julgou-se necessário fazer dessa forma pois se tratava de um diálogo mais direto e como a realizadora estava sozinha para gravar e dirigir, era complicado fazer ambos sem deixar o ambiente desconfortável. Depois de colocar a câmera no tripé, a realizadora afastava-se desta para tentar quebrar a 
relação de distância entre quem está à frente e atrás da câmera. Por essa razão, durante o filme é possível perceber a presença da realizadora evidenciada em algumas imagens, ainda que não intencionalmente.

A primeira imagem do filme, feita por uma criança de sete anos, é confusa, tremida, instável e talvez desconfortável. Entretanto é, ironicamente, a visão mais completa que se tem do espaço ao longo do filme. Ela faz a apresentação do que vai decorrer nos próximos vinte minutos, anuncia os personagens (moradores), as casas, os degraus, a vista, os turistas, as crianças, a ponte e inclusive a própria realizadora. Trata-se da união entre a visão de alguém que realmente conhece o espaço e a falta de inibição de uma criança, que não se incomoda em apontar a câmera para onde bem entende e na velocidade que quer, para apresentar o que tenciona mostrar. Aponta para o rosto das pessoas sem qualquer receio de deixá-las desconfortáveis. Assim é, também, a imagem de Nádia (cinco anos) que leva o espectador para dentro de seu quintal.

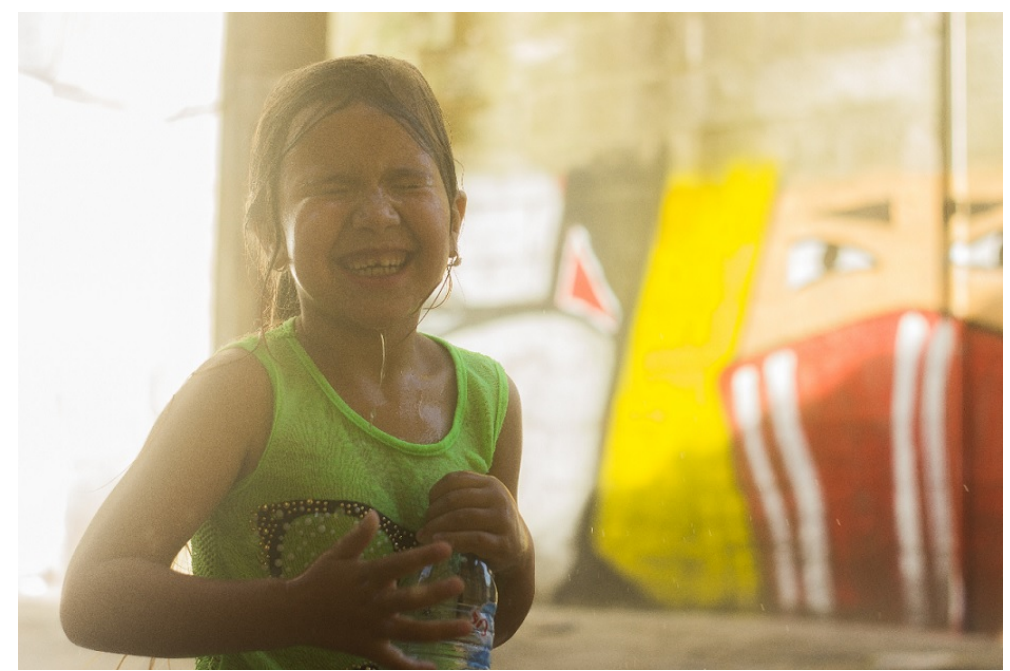

Figura 3. Moradora Nádia a brincar nas escadas na frente de casa. Imagem retirada do filme Caiu um homem ali no quintal.

Autoria: Ana Clara Roberti

Muitas das imagens são filmadas da posição de quem está sentado nos degraus. Algumas pessoas aparecem com as cabeças ou pés cortados pelo enquadramento, a posição varia de cima para baixo e debaixo para cima, de um lado para o outro. Há focagem e desfocagem e cores "estouradas" pela luz do Sol. Entretanto, não seria verdadeiro dizer que não se procurou encontrar maneira de produzir as imagens da melhor forma possível, de acordo, inclusive, com 
os olhos de quem as produziu. Mas é, também, fiel ao trabalho ressaltar que a composição estética não se sobrepôs à forma capaz de revelar o momento tal como decorreu.

Uma simples imagem: inadequada, mas necessária, inexata, mas verdadeira (...). A imagem é aqui o olho da história: sua vocação tenaz para torná-la visível. Mas também está no olho da história: numa zona local, num momento de suspensão visual, assim como se diz do olho do ciclone. (Didi-Huberman, 2003: 56).

\section{Ordenar}

A intenção deste documentário nunca foi se isentar de certa subjetividade por parte de quem o dirigiu. É legítimo dizer que não se procurou distorcer uma realidade, mas sim registrá-la mediante uma forma própria, resultado das opções eleitas ao longo do trabalho.

A escolha do que filmar e de como filmar, já é parte integrante desta subjetividade. Contudo, a edição é a etapa capaz de torná-la mais evidente. Com o mesmo material - a não ser quando se trata de um de vídeo em plano-sequência - é possível ter resultados infinitamente diferentes, que variam conforme a propensão de quem o monta. O resultado é, no caso, uma forma de olhar para uma história e contá-la.

$\mathrm{Na}$ articulação dos planos existe uma mão oculta que fascina a reflexão desconstrutiva contemporânea e que pode também produzir enunciados ou sentido, interagindo ativamente com o modo do sujeito-da-câmera ser na tomada, pelo espectador, determinando a fruição. À mão oculta que articula os planos, alguns chamam montagem. (Ramos, 2008: 86).

Tratando-se do documentário, no que toca à narrativa, a edição é uma etapa com complexidade diferente do que ocorre na ficção. Neste trabalho, é possível dizer que foram esboçados roteiros prévios, o que foi de grande ajuda para guiar, em parte, o que deveria se filmar e, posteriormente, editar. Entretanto, a narrativa só foi devidamente acertada e encadeada, depois da análise de todo o material recolhido e, sendo assim, no momento da montagem

Podemos supor que aquilo que a continuidade consegue na ficção é obtido no documentário pela história: as situações são relacionadas no tempo e no espaço, em virtude não da montagem, mas de suas ligações reais, históricas. (Nichols apud Ramos, 2008: 87).

No filme, o intercalar de planos gerais, afastados e próximos, com histórias fortes e com alguma intimidade, refletem o caminho deste trabalho de investigação. Uma mistura entre imersão e afastamento, sair do micro para se 
compreender melhor o macro, voltando depois ao micro, e assim sucessivamente.

As crianças, por exemplo, têm um papel importante no filme, algo que não estava previsto e só passou a fazer sentido com o material bruto em mãos. Dessa forma, foi possível analisar e compreender o quanto elas foram decisivas no processo de aproximação do local e das pessoas. Inicialmente, eram as crianças as mais desconfiadas, depois, as responsáveis por abrir as portas das próprias casas e por receberem, sempre muito empolgadas, a realizadora. Por muitas vezes, foi mais interessante ver o espaço das escadas pelos olhos delas, capazes de transformar o corrimão em uma brincadeira divertida.

Foi eleito o documentário como objeto final desta investigação, pela sua capacidade de circulação, e por ser capaz de comunicar o conhecimento adquirido de forma abrangente e eficaz. O resultado, o documentário, é o reflexo de uma investigação pela via da imagem e do som.

\section{Roteiro final}

O roteiro aqui apresentado é o resultado do que foi construído antes das filmagens, alterado durante e finalizado na edição. Só foi possível chegar à forma aqui apresentada, depois de concluir todo o processo de montagem. Não se tratando de um guião convencional, este é dividido por blocos, que foram resumidos, com a finalidade de torná-lo mais prático e dinâmico neste artigo.

Caiu um homem ali no quintal

Bloco I (pré créditos): sem qualquer introdução prévia, o espectador se deparada com um plano-sequência de câmera instável, imagem tremida e som confuso. Como forma de instigar a curiosidade e o que está por vir, temse aí a apresentação geral do espaço e dos personagens, que o espectador irá compreender aos poucos ao longo do filme. É a filmagem feita pela moradora Taísa, de 7 anos.

Créditos (Caiu um homem ali no quintal): de forma súbita, corta-se a imagem, mas não o som, e tem-se uma tela preta. Um corte seco seguido do título do documentário. O nome não é didático e é pouco esperado depois do que se viu. Mais uma forma de instigar o espectador, gerar intriga. Só é possível compreendê-lo do meio para o fim do filme.

Bloco II (outra visão do local): composto por um plano do mesmo local que o anterior, mas de forma quase oposta. Imagem estática, poderia ser confundida com uma foto se não fosse o barco que se move lentamente ao fundo no rio e as gaivotas que aparecem. $\mathrm{O}$ espectador começa a se localizar em um momento calmo, não há qualquer personagem na imagem. Ouve-se um rádio ao fundo, quando se percebe que um som forte se aproxima: o metro. Um 
elemento marcante da história que ainda não é visualmente mostrado, apenas se compreende a força do seu som. O metro passa e volta-se a escutar o rádio. Também se apresentam algumas imagens do local com moradores, cenas corriqueiras no espaço.

Bloco III (apresentação das personagens): Com alguns planos curtos, mas que são capazes de expressar certas peculiaridades individuais, o espectador é apresentado às pessoas que irão guiar o filme.

Bloco IV (contextualização do local e a relação com as pessoas): Momento em que se conhece melhor os moradores destacados no documentário. Falam em diálogo direto, contam sua história no local (são moradores antigos), destacam a diferença de como eram as escadas antes e de como é agora.

Bloco V (morfologia): Fase que dá destaque à morfologia peculiar do local. Há situações que só acontecem com aquelas pessoas, visto que vivem no meio das escadarias. Relatos sobre fatos excepcionais e corriqueiros para os moradores.

Bloco VI (o metro): Etapa em que se discorre sobre o que alterou no local com a chegada do metro. As consequências são diferentes conforme os moradores e as opiniões também.

Bloco VII (futuro): momento dedicado à visão dos moradores com relação ao futuro nas escadas.

*Transições: entre os blocos, como forma de fazer com que o espectador se habitue e compreenda melhor o modo de vida das pessoas nas escadas, há imagens sem diálogo direto, apenas refletindo o registro do que aparece e acontece no local.

* Áudio: o som do metro entra no meio das conversas e as sobrepõe. Nenhum desses momentos foi retirado ou abrandado. Eles enfatizam como as pessoas lidam com essa realidade, continuam a conversar normalmente sem alterar sequer o tom de voz, já que para elas é algo normal.

\section{Conclusão}

O presente artigo enfrentou o desafio de enunciar e refletir sobre o modo de registrar o cotidiano de uma comunidade urbana através da imagem e do som, pela experiência de um trabalho de campo imersivo no local. Registro este, iniciado pela tentativa de compreender por meio da produção de reportórios fotográficos e videográficos, a permeabilidade entre o público e o privado nas escadarias do centro do Porto, tendo como objeto final um filme documentário. Tal permeabilidade é ilustrada através das imagens captadas ao longo do trabalho de campo e da imersão da câmera no local, que demonstram como os moradores utilizam e vivenciam o espaço das escadarias, ou seja, para além 
dos limites físicos de suas residências, como extensão de suas próprias casas. Como, por exemplo, os planos das senhoras sentadas a conversar nas escadas e a comer como se estivessem na sala de casa ou as crianças ainda de pijama a brincar nos corrimãos.

A coleta do material desta investigação, resultante em conhecimento teórico e prático, foi realizada através do trabalho de campo e, sendo assim, em contato direto com o local e as pessoas que o habitam; pela apresentação do projeto aos moradores, demonstrando o interesse que o local havia despertado em alguém de fora daquele ambiente, com a apresentação do material imagético produzido e, principalmente, através das conversas exploratórias. Este estudo acredita ter sido capaz de estimular os que ali vivem a refletir sobre a maneria como lidam com o local e a pensar sobre sua própria história envolvida nesse ambiente. Em seguida, apresenta-se um conjunto de exemplo que justificam tal afirmação:

- No decorrer do trabalho, as pessoas referiram que em alguns momentos não davam valor ao local onde viviam, mas percebiam o quanto tinham "sorte" em habitar aquele local, no centro da cidade, com boa vizinhança e com vistas "bonitas".

- Ao olharem para as fotografias, feitas no âmbito do projeto, apresentadas pela investigadora, os moradores comentavam sobre o local, relembrando episódios e pessoas. Gostavam do que viam em alguns momentos, em outros constatavam o abandono atual e falavam sobre tal questão. Ainda que fosse uma paisagem com a qual lidavam todos os dias, ao olhar para as fotografias pareciam descobrir mais sobre o local onde viviam.

- Durante a exibição do filme se sentiram orgulhosos do local onde vivem, pediram para voltar para fazer "outro" filme, que conte ainda mais histórias sobre o local.

Acredita-se que o documentário produzido conseguiu buscar alternativas ao documentário padrão televisivo, na medida em que as imagens utilizadas são resultado da imersão de mais de um ano da realizadora nas Escadas das Verdades e do Codeçal. Trata-se, portanto, de um material conseguido com paciência e por meio de estratégias capazes de tornar a câmera o mais confortável possível, resultando em imagens espontâneas. As opções de estilo tomadas durante a edição, preocuparam-se em revelar a história e o cotidiano do local, mas também em refletir o percurso deste projeto.

Este projeto de documentário acredita ter ido além do plano inicialmente proposto. O contato com o local, as pessoas encontradas ao longo deste processo e a imersão em tal realidade peculiar - tratada aqui como diferente e 
não exótica - foram os responsáveis por alargar a visão inicial. Confirmase, a partir disso, a importância de principiar o trabalho de campo disponível e suscetível a absorver os imprevistos que este pode oferecer ao documentário. O abandono do local, visível aos poucos olhos que por ele passam, é uma questão complexa, uma preocupação constante dos moradores das Escadas das Verdades e do Codeçal. Durante o estudo, foi possível compreender que a comunidade que despertou atenção pelo seu caráter vivo e espontâneo, tem um futuro incerto e bem diferente do presente - e ainda mais do saudoso passado.

A vivência pessoal junto ao local e a imersão gradativa em seu cotidiano foram inspiradoras para a criação do objeto final deste estudo: o documentário Caiu um homem ali no quintal. A nível individual, para a realizadora, a forma de olhar e viver no Centro Histórico no Porto, mudou. Esta procura de compreender o cotidiano das comunidades do local de análise deste projecto, alterou a forma de olhar a mistura existente entre a complexidade e a simplicidade das ruas e da malha urbana.

\section{Referências bibliográficas}

Barnouw, E. (1993). Documentary: a history of the non-fiction film. Oxford: Oxford University Press.

Benjamin, W. (2006). Passagens. Brasil: UFMG.

Brandão, D. (2014). Museum of Ransom: Towards a system for the aggregation and interpretation of contemporary participatory video as contextual cultural heritage. (PhD). Porto: Universidade do Porto.

Coutinho, E. (2009). A entrevista como método: uma conversa com Eduardo Coutinho. In F. Frochtengarten (Ed.). Brasil: Universidade de São Paulo.

Daminello, L.A. (2010). Entre duas margens: do filme etnográfico ao cinémavérité e o lugar do filme la pyramide humaine na obra de Jean Rouch. (Mestrado). São Paulo: Universidade Estadual de Campinas.

Debord, G. (1958). Théorie de la derive. Revista Internacional Situacionista, 2.

Didi-Huberman, G. (2003). Images malgré tout. Paris: Les Editions de Minuit.

Flick, U. (2005). Métodos qualitativos na investigação científica, $1^{\text {st }}$ ed. Lisboa: Monitor.

Mass Observation. (2004). Disponível em: http://www.massobs.org.uk

Puccini, S. (2012). Roteiro de documentário: Da pré-produção à pós-produção. Campinas, SP: Papirus. 
Ramos, F.P. (2008). Mas afinal... O que é mesmo documentário?. São Paulo: Senac.

Rouch, J. (1995). Os pais fundadores: dos antepassados totémicos aos investigadores de amanhã. Lisboa: Imagens do Mundo: Mostra de Cinema Etnográfico Francês.

Rouch, J. \& Feld, S. (2003). Ciné-Ethnography, Minneapolis: University of Minnesota Press.

\section{Filmografia}

Edifício Master (2002), de Eduardo Coutinho.

O fim e o princípio (2006), de Eduardo Coutinho.

Sur le passage de quelques personnes à travers une assez courte unité de temps (1959), de Guy Debord. 